\title{
Effect of cryogenic treatment on microstructure and wear characteristics of AISI M35 HSS
}

\author{
D. Candane ${ }^{1, *}$, N. Alagumurthi ${ }^{2}$, K. Palaniradja ${ }^{2}$ \\ ${ }^{1}$ Department of Mechanical Engineering, Women's Polytechnic College, Pondicherry, India \\ ${ }^{2}$ Department of Mechanical Engineering, Pondicherry Engineering College, Pondicherry, India
}

\section{Email address:}

d_candane@yahoo.co.in (D. Candane)

\section{To cite this article:}

D. Candane, N. Alagumurthi, K. Palaniradja. Effect of Cryogenic Treatment on Microstructure and Wear Characteristics of AISI M35 HSS, International Journal of Materials Science and Applications. Vol. 2, No. 2, 2013, pp. 56-65. doi: 10.11648/j.ijmsa.20130202.14

\begin{abstract}
Cryogenic treatment has been widely acknowledged as a means of improving wear resistance of tool materials. A Comparative study on conventionally heat treated and cryogenic treated AISI M35 grade high-speed steel specimens has been presented in this paper. Specimens initially subjected to conventional heat treatment at austenitizing temperature of $1200^{\circ} \mathrm{C}$ were subsequently subjected to shallow cryogenic treatment at $-84{ }^{\circ} \mathrm{C}$ for 8 hours and deep cryogenic treatment at $-195^{\circ} \mathrm{C}$ for 24 hours followed by double tempering at $200^{\circ} \mathrm{C}$. Presence of retained austenite was studied at the end of each of the above treatment using XRD analyzer. An estimated 19\% retained austenite present at the end of conventional heat treatment was reduced to $5 \%$ at the end of shallow cryogenic treatment, while deep cryogenic treatment practically removed all traces of austenite in the sample. Changes in the microstructure were studied using SEM. Fine precipitates of carbides of size $0.3-0.5 \mu$ were observed in cryogenically treated samples. Variation in mechanical properties such as toughness and hardness has been studied. There was no change in toughness due to cryogenic treatment and it corroborates well with the results of fractography. Wear characteristics were studied using pin on disc wear tester. The operative modes and mechanisms of wear have been identified as severe delaminative and mild oxidative from the morphology of worn surface of pin. The results unambiguously confirm enhancement in hardness and wear resistance of cryogenically treated specimens.
\end{abstract}

Keywords: High - Speed Steel, Cryogenic Treatment, Wear Resistance, Retained Austenite, Martensite, Morphology, Fractography

\section{Introduction}

Use of cryogenic treatment in enhancing properties of tool materials has received wide acceptance by researchers and industries, recently. The research publications during the past two decades show an increase in interest, on the use of cryogenic treatment, on various cutting tool mate- rials [1,2,4,7,8,10,12,15-17], die materials[5] and bearing materials [3] to exploit the positive effects of such a simple and cost effective technique. Improvements in hardness, fatigue resistance, toughness, and wear resistance of cryo-genically treated materials, have been reported invariably in every scientific publication. Specifically, reports on the improvement in tool life of a wide variety of cutting tool materials $[7,10,15]$, due to the use of cryogenic treatment, has attracted the attention of cutting tool industries and manufacturing sector, since it is going to have a remarkable impact on improving economy of production.

Tool life is a major factor that is considered in production planning itself since it affects tool changing strategies and throughput time of finished product in any manufacturing industry. Hence any improvement in tool life will have a direct impact on the cost of production, tool changing time and indirectly help achieve production target. The ever increasing demand for cutting too materials, has been driving force behind the development of newer cutting tool materials each successor having superior feature than the predecessor. Carbon- tool steels were in use until the intro-duction of high- speed steels in the beginning of 19th century followed by cast alloys around 1915. Later, inserts of car-bides, cermets, ceramics with excellent hardness and at higher cutting speeds, produced by powder metallurgy re- volutionized metal cutting in terms of their cutting speed and materials removal rate.

Subsequently ultra hard materials such as UCON, BORAZON, CBN, PCBN and PCD emerged with cutting speeds five to eight times that of carbides. The high-speed steel, though introduced a century ago, with time, it has 
undergone several modifications, resulting in a wide variety of grades enabling it versatile for wide ranging metal cutting applica-tions. Though the high- speed steel is being replaced in certain sectors it cannot be fully phased out, since, it is the most ideal tool material for operations such as drilling, tapping and reaming where the economic cutting speed is too low for its competitors [2]. In case of deep drilling operations high-speed steel is the most ideal and extremely unique in performance due to its ability to absorb shocks and vibra-tions during drilling. Tool breakage costs are quite high with the use of carbide tools and the worst case is the salvaging and regrinding of carbide tools is very difficult due to their high hardness. In case of gear hobbing tool and broaching tool, high-speed steels are preferred over carbide tools pri-marily because of exorbitant replacement cost involved and difficulties in repairing of such tools. Due to the above reasons high - speed steel, still dominates shop floor in many a manufacturing sectors due to its unique toughness and economic price over the modern cutting tool materials.

Though addition of alloying elements confers the desired cutting characteristics making it suitable for a specific metal cutting application, it adds to the cost of the material with increasing content of cobalt and tungsten. In addition to alloying, further enhancement in wear resistance and tool life is made possible by use of hard abrasive coating, over the functional part of the tool [2]. But, once the abrasive layer wears out the wear resistance switches back to that of plain tool. Cryogenic Treatment (CT) is another option available that helps improve the wear resistance and life of tool, by bringing about property changes across the entire volume of the material unlike the coated tools where in the enhance-ment in wear resistance takes place only at the surface of the tool $[1,2,8,12,16,17]$. Hence after every regrinding the ad-vantages of CT can be brought back into full play.

Until the end of 1960 the idea of sub zero treatment was attempted by directly immersing metallic components and tools in liquid nitrogen $[13,14]$. High brittleness, cracking of components due to thermal shock and volumetric expan-sion of treated components was reported in many cases [12]. Advancements in the field of refrigeration cycles was made use by Bush (Cryo Tech, Detroit, MI) in developing CT system towards the end of 1960s and it was further im-proved by Paulin (300 Below Inc., Decatur ,II) with a tem-perature feedback control on heating and cooling rates that allowed to perform effective and crackless CT. Application of CT on machine tools was investigated by Barron R.F. in 1980s .Improvement in hardness and wear resistance was attributed to the transformation of retained austenite and fine precipitates of carbides[12].

Popandopulo and Zhukova studied the transformation during $\mathrm{CT}$ and they reported a volume reduction in the temperature range of -90 and $+20^{\circ} \mathrm{C}$ [22]. They attributed volumetric reduction to contraction of crystal lattice partial decomposition of martensite, precipitation of carbon atoms at dislocation sites and formation of ultramicroscopic car-bides during CT.

Martensite formed during quenching operation is in me-tastable condition at room temperature [21]. Any change in microstructure and condition of martensite could be possible only by creating temperature difference. Lipson (1967) studied the effect of cryogenic treatment on grain size and suggested that the $\mathrm{CT}$ reduces grain size by $1-4 \%$. Reduction in grain size would result in improvement in wear resistance [3]. CT brings about thermal instability to martensite by means of supersaturating it with carbon which further leads to migration of carbon atoms and atoms of alloying ele-ments to the nearby lattice defects and segregate there [1].Which on further warming up and tempering results in the formation of fine carbides.

Flavio J. da Silva studied the effect of cryogenically treated AISI M2 grade high -speed steel tools and reported complete transformation of retained austenite and no im-provement in hardness value [2]. A maximum of $44 \%$ im-provement in tool life under Brandsma rapid facing test was observed. Improvement in tool life $65-343 \%$ in case of twist drills was reported. Overall the CT had a favourable im-provement on the life of tools tested.

Firouzdor .V studied the effect of deep cryogenic treat-ment on wear resistance and tool life of M2 HSS drill [1]. An increase of $77 \%$ and $126 \%$ in tool life of cryogenic treated and cryogenic treated tempered drills was reported. Wear resistance improvement was attributed to the fine precipi-tates of carbides during $\mathrm{CT}$.

S.Harish studied the effect of cryogenic treatment on the microstructure and hardness of En 31 bearing Steel [3]. There was no appreciable change in toughness. Increase in hardness $13-14 \%$ in case of deep cryogenic treatment (DCT) was reported. Formation of carbide particles at the end of tempering process in confirmed. To promote precipitation of secondary carbides tempering should be done which is es-sential for hardness augmentation and wear resistance im-provement.

Akhbarizadeh studied the effect of cryogenic treatment on the wear behavior of D6 Tool Steel[4]. DCT has more chromium carbides compared to shallow cryogenic treat-ment (SCT) and also due to complete elimination of retained austenite in DCT specimen the wear resistance of DCT specimen was much higher. Also stabilized samples showed improvement in hardness after one week than the non sta-bilized samples.

D. Das studied the influence temperature of sub zero treatment on wear behavior of die steel [9]. Lower the temperature of sub zero treatment higher is the improvement in wear resistance. Reduction in retained austenite asso-ciated with simultaneous increase in secondary carbide precipitation.D. Das studied the correlation of microstructure with the wear behavior of deep cryogenic treated AISI D2 Steel. DCT markedly enhances wear resistance than shallow cryogenic treatment. Also DCT completely eliminates re-tained austenite with the concurrent increase in secondary carbides while shallow cryogenic treatment reduces only considerable amount of retained austenite. 
Presence of austenite at the end of conventional heat treatment process is inevitable [21]. Austenite the softest phase present in the steel acts as weak spot and its presence is very sensitive and critical in cutting tools because tool wear begins only at these sites by the ploughing action of hard particles in the work piece during machining. Rate of cooling has a profound effect on the transformation of austenite to martensite. If rate of cooling is high it tends to lower the martensite transformation start temperature (Ms). Even for eutectoid steel with $0.78 \%$ of Carbon, at normal cooling rates the commencement of martensite transformation is lowered by $20^{\circ} \mathrm{C}$. The martensite transformation reaches completion only at $-50^{\circ} \mathrm{C}$. Whereas the cooling rates fol-lowed during heat treatment of HSS are much higher and obviously there is a consequent reduction in the Ms. Presence of alloying elements is another major factor that tends to lower the Ms temperature [3].The following equation shows the effect of alloying elements in lowering the Ms (martensite transformation start temperature) and Mf (martensite transformation finish temperature) [3].

$$
\begin{gathered}
\mathrm{Ms}=539-423(\mathrm{C})-30.4(\mathrm{Mn})-12.1(\mathrm{Cr})-17.7(\mathrm{Ni})-7.5 \\
(\mathrm{Mo}) \ldots .{ }^{\circ} \mathrm{C} \\
\mathrm{Mf}=\mathrm{Ms}-215 \ldots .{ }^{\circ} \mathrm{C}
\end{gathered}
$$

As a consequence the transformation of austenite to martensite may be completed only at sub zero temperatures. In the conventional heat treatment process, at the end of quenching, the lowest temperature experienced is that of room temperature, resulting in incomplete transformation of austenite to martensite. Hence during the cryogenic treat-ment transformation of retained austenite to martensite restarts. Sizable amount of conversion of retained austenite to martensite takes place in case of shallow cryogenic treatment while the deep cryogenic treatment completely eliminates the traces of austenite in a many cases. Lower the temperature higher is the transformation of retained auste-nite to martensite and hence temperature of $-196^{\circ} \mathrm{C}$ is pre-sently used in the case of deep cryogenic treatment [5].

\section{Cryogenic Treatment}

Cryogenic Treatment (CT) of tool materials consists of three stages, that involves cooling of tool material from room temperature, at an extremely slow rate ranging from 0.5 to $1{ }^{\circ} \mathrm{C} / \mathrm{min}$, to temperature as low as $-84^{\circ} \mathrm{C}$ for Shallow Cryogenic Treatment (SCT) and $-196{ }^{\circ} \mathrm{C}$ for Deep Cryo-genic Treatment (DCT), followed by soaking for a period ranging from 24 to 36 hours and finally heating up at the rate of 0.5 to $1{ }^{\circ} \mathrm{C} / \mathrm{min}$, to room temperature [12]. Though Cryogenic Treatment has been around for many years it is truly in its infancy when compared to heat-treating. Scien-tific publications on the use of CT on tool materials are spotty and subjective. Therefore it requires rigorous expe-rimentations and investigations to ascertain and evaluate the process before commercial exploitation could begin.

\section{Methodology}

\subsection{Specimen Preparation}

Since it is a comparative study two sets of specimens have been prepared for all tests. Specimens were prepared from AISI M35 HSS bar of $15 \mathrm{~mm}$ square cross section with a nominal composition of $\mathrm{C}-0.889 \%, \mathrm{Mn}-0.273 \%, \mathrm{Si}-$ $0.364 \%, \mathrm{~S}-0.006 \%, \mathrm{P}-0.024 \%, \mathrm{Cr}-4.175 \%$, Ni $-0.171 \%$, Mo - 4.656\%, V - 1.788\%,W - 6.087\%, CO - 4.551\%. Suitable allowances have been adopted to account for surface preparations as necessary in case of laboratory tests.

\subsection{Conventional Heat Treatment}

Initially all the specimens were subjected to conventional heat treatment in a barium chloride salt bath furnace in the following sequence. As a first step specimens were preheated in a forced air circulation furnace maintained at a tem-perature of $500{ }^{\circ} \mathrm{C}$ to remove the moisture content for a period of 30 minutes. Later they were transferred to salt bath pre heating furnace maintained at a temperature of $900{ }^{\circ} \mathrm{C}$ for a period of 7 minutes. Subsequently the lot was trans-ferred to hardening furnace maintained at $1200{ }^{\circ} \mathrm{C}$ for austenitization to occur for a period of 2 minutes. The specimens were swiftly transferred and quenched in salt bath furnace maintained at $560^{\circ} \mathrm{C}$ for a period of 15 minutes for stabilisation to occur. And finally the lot was air cooled up to room temperature. After confirming the as quenched hardness the specimens were triple tempered in salt bath furnace maintained at a temperature $570{ }^{\circ} \mathrm{C}$. In each tempering cycle after reaching $570{ }^{\circ} \mathrm{C}$ the specimens were soaked for a period of 90 minutes for stabilisation to occur, followed by air cooling up to room temperature.

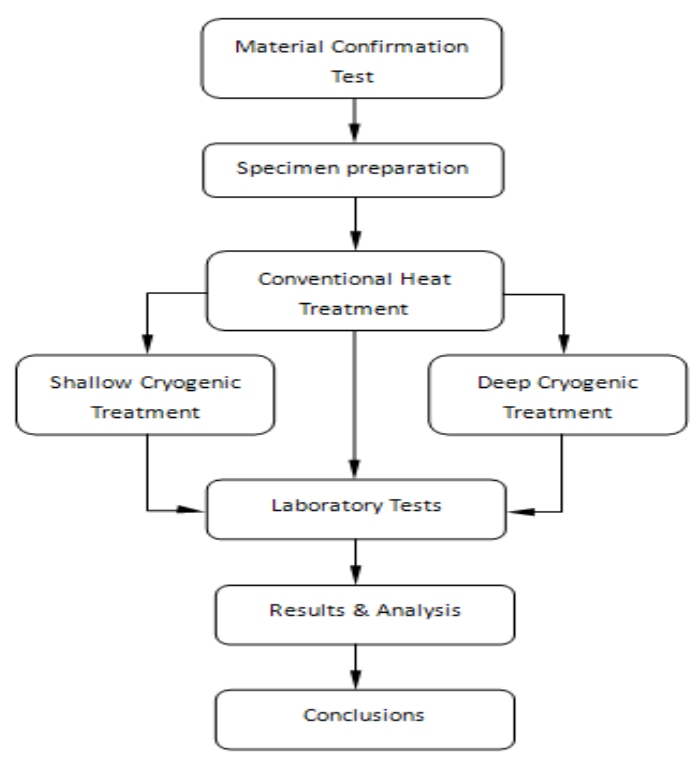

Fig. 1. Schematic diagram showing the methodology adopted.

\subsection{Cryogenic Treatment}

Cryogenic treatment involves the following sequence: 1. Slow cooling to predetermined low temperature 
2. Soaking for predetermined amount of time

3. Slow heating to room temperature

4. Tempering

Before proceeding for cryogenic treatment the batch of conventionally heat treated specimens was cleaned to re-move the dirt, impurities and traces of salt layer found on their surface.

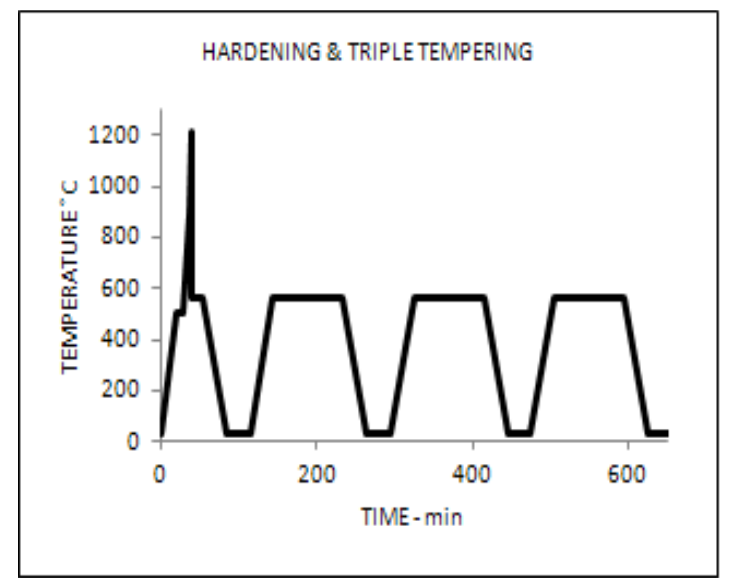

Fig. 2. Conventional heat treatment cycle followed for AISI M35 HSS.

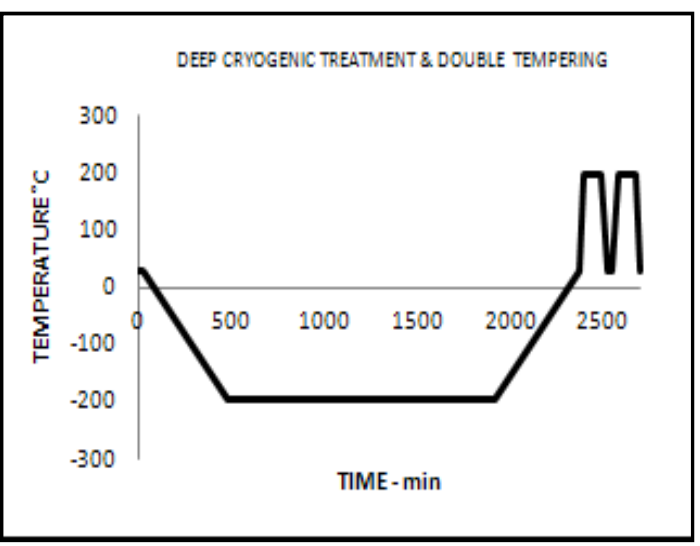

Fig. 3. Cryogenic treatment applied to conventionally heat treated AISI M35 HSS specimens.

\subsection{Shallow Cryogenic Treatment}

Shallow cryogenic treatment has been carried at $-85^{\circ} \mathrm{C}$ with a soaking time of 8 hours. Since rate of cooling is a very sensitive factor and it seriously affects the results of cryo-genic treatment, the specimens were very slowly cooled at the rate of $-0.5^{\circ} \mathrm{C} / \mathrm{min}$, until they reach the final soaking temperature of $-85^{\circ} \mathrm{C}$ [12]. A soaking period of 8 hours was adopted to allow for transformation reactions to take place after which the cycle was reversed such that temperature builds up at the rate of $0.5^{\circ} \mathrm{C} / \mathrm{min}$ up to room temperature.

\subsection{Deep Cryogenic Treatment}

Deep cryogenic treatment has been carried at $-195^{\circ} \mathrm{C}$ with a soaking time of 24 hours. Specimens were cooled at the rate of $-0.5^{\circ} \mathrm{C} / \mathrm{min}$ until they reach the final soaking tem-perature of $-195^{\circ}$ C. Soaking time of 24 hours was adopted to allow for complete phase transformation to take place. Then the cycle was reversed such that temperature ramp up at the rate of $0.5^{\circ} \mathrm{C} / \mathrm{min}$ up to room temperature.

\subsection{Low temperature Tempering}

Tempering at $200^{\circ} \mathrm{C}$ with 90 minutes soaking is essentially to be followed after cryogenic treatment. The carbon dif-fused during cryogenic treatment forms aggre gates . Since the martensite resulting from transformation of retained austenite during cryogenic treatment results in brittleness and also as there is a $4 \%$ volumetric expansion during the transformation of austenite internal stresses creep in. To alleviate brittleness, relieve internal stresses and to allow for precipitates of fine carbides specimens were double tem-pered in forced air circulation furnace.

\section{Results and Analysis}

\subsection{XRD Analysis of Phases}

Presence of austenite is inevitable at the end of quenching during the heat treatment of high-speed steels. The diffusion of carbon is sufficiently suppressed for hard martensite to form instead of softer $\alpha-\mathrm{Fe}+$ carbide aggregate. The rate of cooling, cooling temperature and alloy composition will determine how much austenite will be 'retained' in the microstructure at room temperature [21]. For eutectoid steel with $0.8 \% \mathrm{C}$ the martensite transformation completes only at $-50^{\circ} \mathrm{C}$ [22]. Where as in the conventional heat treatment the material is cooled only up to room temperature. As a result there is a break in transformation of austenite to martensite during conventional heat treatment. The pres-ence of austenite has significant consequences in crucial metallurgical applications such as metal cutting. To monitor austenite content, X-ray diffraction method has been found to be most effective and accurate. The phases present in the Conventional Heat Treated and Cryogenic Treated Specimens have been studied using X-Ray Diffractometer. The X-Ray diffraction pattern (Fig.4) showed that austenite, martensite and carbides of chromium and tungsten are the major phases present in the sample at the end of conven-tional heat treatment. Amount of retained austenite present at the end of conventional heat treatment was found to be 17-19\% .Presence of retained austenite in both shallow and deep cryogenic treatment has been found to be $4-5 \%$ and less than $1 \%$ respectively. During cryogenic treatment con-traction in lattice of martensite and austenite took place. Due to super saturation martensite with carbon and ther-modynamic instability the carbon atoms squeezed out of martensite, migrated to the neighbouring lattice defects and acted as nucleation sites for the growth of fine carbides. Upon tempering fine precipitates of carbides were formed, with concurrent softening of martensite. The X-Ray dif-fraction pattern (Fig.5) corresponding to deep cryogenic treatment showed no traces of austenite but increase in percentage of carbides by about $2 \%$. 


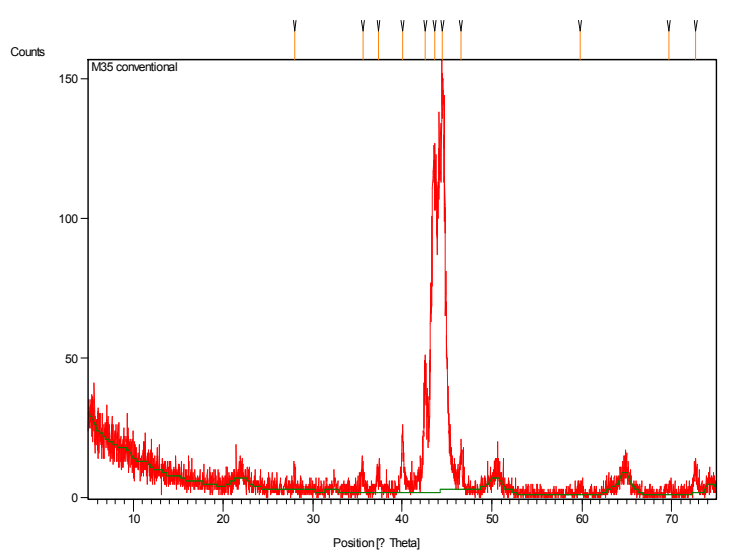

Fig. 4. X-Ray Diffraction Pattern of Conventional Treated AISI M35 HSS.

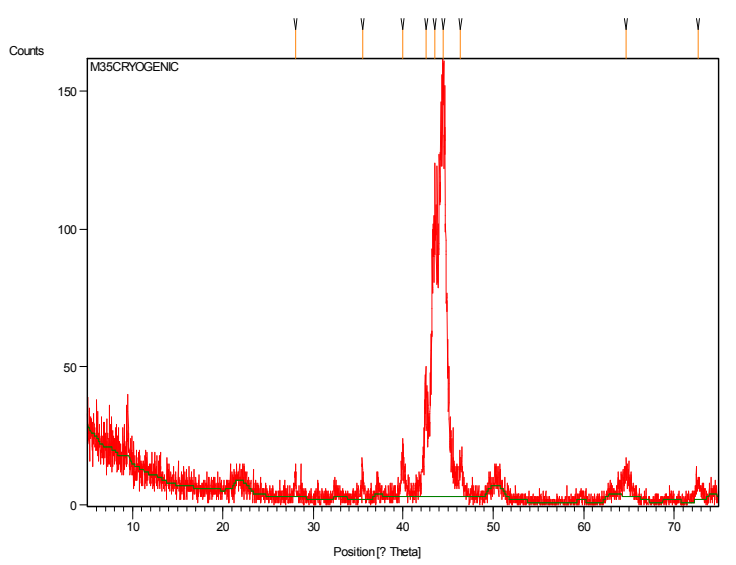

Fig.5. X-Ray Diffraction Pattern of Deep Cryogenic Treated AISI M35HSS.

Since traces of retained austenite is almost completely eliminated only in the case of deep cryogenic treatment further studies such as impact energy and wear test were done only for deep cryogenic treated specimens.

\subsection{Hardness Test}

Hardness of specimens subjected to conventional heat treatment (CHT), shallow cryogenic treatment (SCT) and deep cryogenic treatment (DCT) have been presented in the following table. A minimum of four tests were conducted as per IS 1586 - 2000(RA2006) and ASTM E384-10 guidelines for measurement of bulk hardness and micro hardness respectively. The average value of hardness is presented in Table.1.Increase in hardness of cryogenically treated sam-ples is due to the conversion of retained austenite to martensite and due to the presence of fine carbides in the metal matrix.

Table 1. Results of Hardness Test.

\begin{tabular}{lccl}
\hline SL.No. & CHT & SCT & DCT \\
\hline HRC & 64 & 64.5 & 65.5 \\
Vickers & 920 & 934 & 980 \\
Hardness & 920 & \\
\hline
\end{tabular}

\subsection{SEM Analysis}

Sample was cut across pin of diameter $10 \mathrm{~mm}$ and length $20 \mathrm{~mm}$, moulded using thermosetting resin, then ground progressively with finer $\mathrm{SiC}$ water proof papers from 120 to 1000 grit to produce polished flat surface. The surface was etched using 2\% nital and cleaned using alcohol. During etching the atoms at the grain boundaries react more with the etchant than the atoms within the grains. As a result the grain boundaries will be clearly visible during microscopic ob-servations as dark field compared to the interior of the grains. In the case of conventional heat treated specimen the presence of primary M6C carbides in the matrix of marten-site is very clearly observed. Moreover the primary carbides are clustered along with other carbides. Also the presence of micro voids is observed. The shallow cryogenic treated specimen reveals a homogeneous distribution of primary M6C carbides and precipitation of secondary M6C carbides. Still some micro voids are observed.

The deep cryogenic treated specimen reveals precipitation of more number of secondary M6C carbides and their size refinement. Secondary carbides of size ranging 0.3-0.5 were observed in the deep cryogenic treated specimen. Precipi-tates of fine carbides are mostly along the grain boundary of the deep cryogenic treated specimen.

Fig. 10 and Fig. 11 are the representative samples of energy dispersive X-Ray spectrum from carbide particles of con-ventionally heat treated and deep cryogenically treated specimens, in polished and etched condition. Further the population of carbide particles is quantified using image analyser from at least 10 areas.

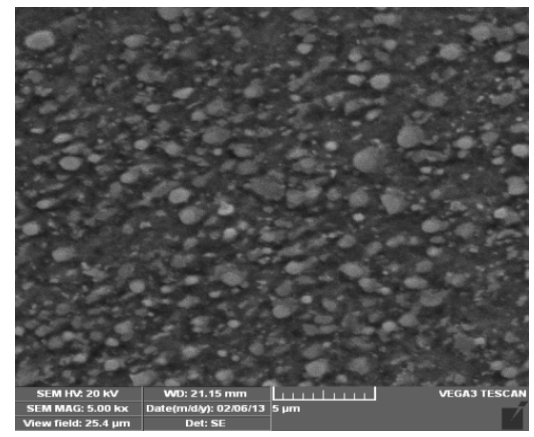

Fig. 6. SEM image at 5000X magnification indicating the alloying elements of raw AISI M35 Specimen.

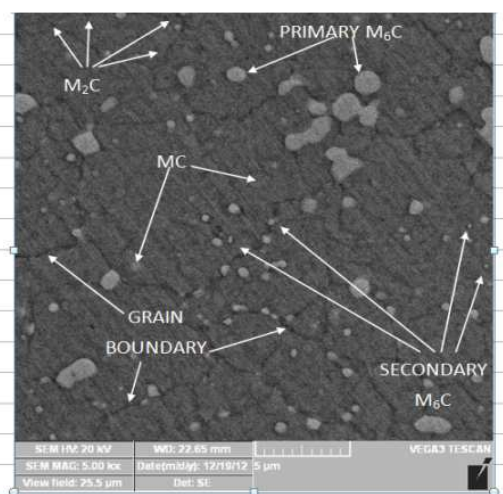




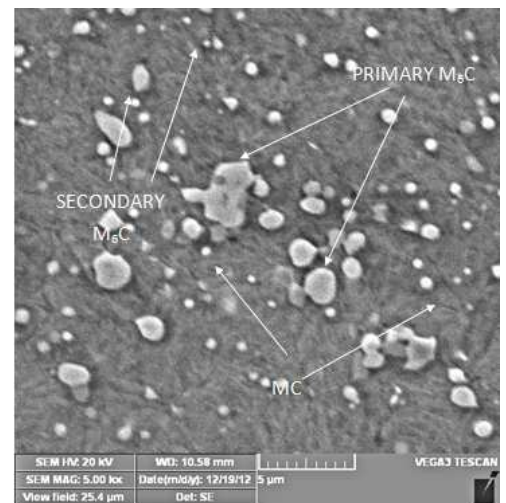

Fig. 7. SEM image of Conventionally Heat Treated, AISI M35 HSS,Specimen.

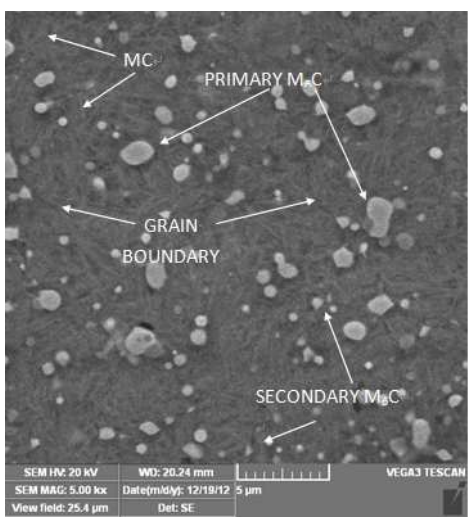

Fig. 8. SEM image of Conventionally Heat Treated and Shallow Cryogenic Treated AISI M35 HSS Specimen.

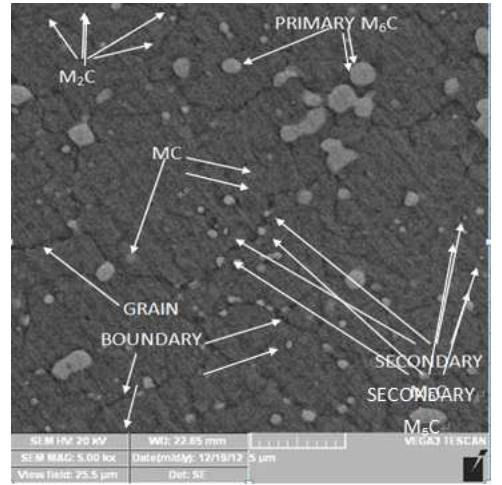

Fig. 9. SEM image of Conventionally Heat Treated and Deep Cryo-genically Treated AISI M35 HSS Specimen.

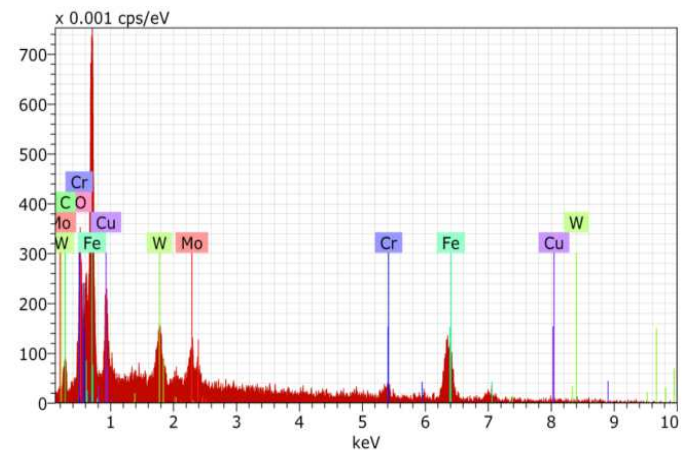

Fig. 10. SEM EDX Spectrum of CT AISI M35 HSS specimen.

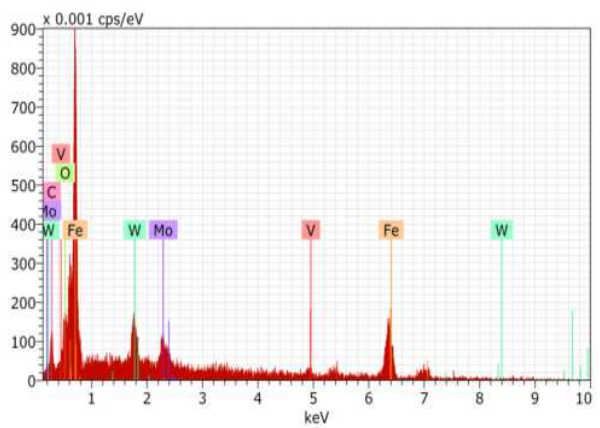

Fig. 11. SEM EDX Spectrum of DCT specimen.

\subsection{Impact Test Results}

To study the effect of cryogenic treatment on the toughness of AISI M35 specimens, the impact test was performed as per ASM guidelines. The as quenched speci-men due to its brittle nature showed a toughness value of $4 \mathrm{~J} / \mathrm{mm} 2$ and it improved to $4.5 \mathrm{~J} / \mathrm{mm} 2$ upon triple tempering. Subsequently due to the transformation of retained aus-tenite into martensite during cryogenic treatment, brittleness crept in, due to which there was a slight drop in toughness value from 4.5 $\mathrm{J} / \mathrm{mm} 2$ to $4.3 \mathrm{~J} / \mathrm{mm} 2$. Again, during subse-quent double tempering at $200^{\circ} \mathrm{C}$ the internal stresses were relieved and the martensite was conditioned with a conse-quent improvement in toughness. Therefore, there was no loss of toughness due to cryogenic treatment.

Table 2. impact test results.

\begin{tabular}{lcll}
\hline \multicolumn{2}{ll}{ Energy Absorbed $\mathbf{J} / \mathbf{m m} 2$} & \multicolumn{2}{l}{} \\
\hline \multicolumn{2}{ll}{ Conventional Heat Treatment } & \multicolumn{3}{l}{ Cryogenic } & Treatment \\
\hline As Quenched & Tempered & $\begin{array}{l}\text { Cryogenic } \\
\text { Treated }\end{array}$ & Tempered \\
\hline 4 & 4.5 & 4.3 & 4.5 \\
\hline
\end{tabular}

\subsection{Fractography Results}

Morphology of fractured surfaces was studied using SEM images at 5000X magnification. Fractured surfaces of specimen used for Charpy impact tests in as quenched, as quenched + triple tempered, as quenched + triple tempered + deep cryogenically treated and as quenched + triple tem-pered + deep cryogenically treated + double tempered con-dition were studied for correlating the effect of various treatments applied to them.

Fractograph corresponding to as quenched specimen shows the presence of many quasi cleavage facets and dimples. Many small sized facets formed during cleavage are also observed. Fracture took place in regions containing inclusions of M6C carbides by dimple rupture. Presence of micro cracks might be due to the brittleness of the martensite in untempered condition. Many micro voids have been formed because the carbide particles got pulled off ab-sorbing impact energy during rupture.

The presence of equi-axed dimples in the fractography (Fig.9) shows that there is an improvement in ductility after triple tempering the as quenched specimen. Fracture 
oc-curred in the regions of inclusions by dimple rupture.

Unlike the other fractographs the one found here (Fig.10) has many micro cracks and very few dimples. Presence of more micro cracks indicates the excessive brittleness that creeps in due to the transformation of retained austenite to martensite. Flat facets and irregular quasi cleavage facets indicate that the failure occurred predominantly by brittle facture.

More number of fine precipitates of carbides is clearly evident in after low temperature tempering of cryogenically treated specimen. Presence of different sized dimples indi-cates precipitates of more carbides after double tempering of cryogenically treated specimen.

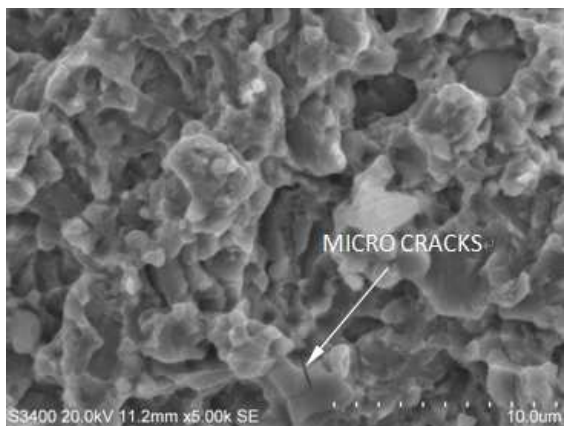

Fig. 12. SEM image of Fracture of as Quenched AISI M35 HSS specimen during Charpy impact Test.

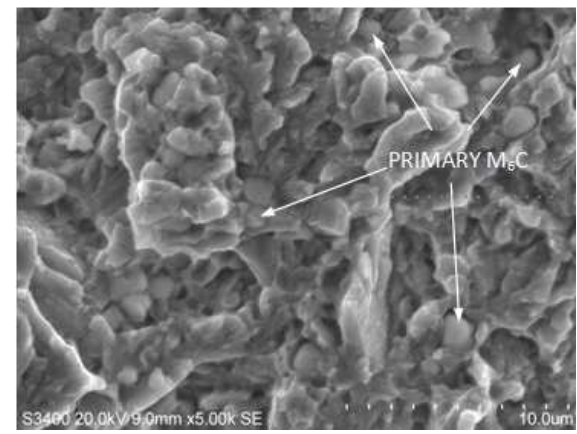

Fig. 13. SEM image of Fracture of Quenched and triple tempered AISI M35HSS specimen during Charpy impact Test.

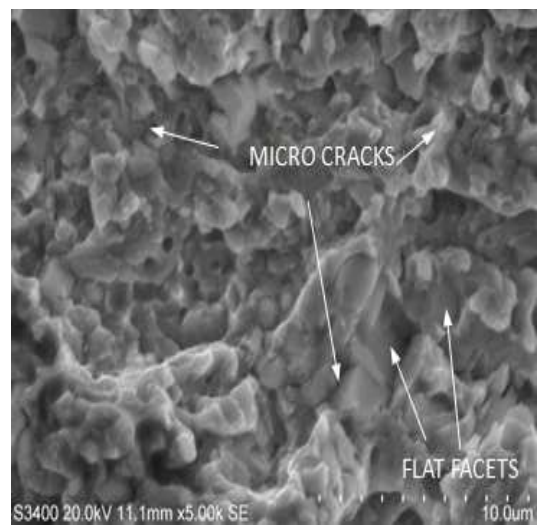

Fig. 14. SEM image of Fracture of specimen conventionally heat treated and deep cryogenically treated AISI M35 HSS specimen during Charpy impact Test.

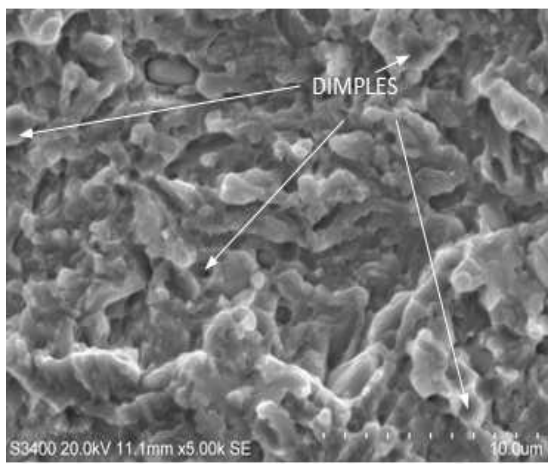

Fig. 15. SEM image of Fracture of specimen conventionally heat treated and deep cryogenically treated and double tempered AISI M35specimen during Charpy impact Test.

\subsection{Wear Test Results}

Wear resistance tests were carried out on conventional heat treated specimens and deep cryogenic treated speci-mens. Shallow cryogenic treated specimens were not con-sidered for wear studies. Ducom Pin on Disc wear tester was used for conducting pin on disc wear study. Cylindrical pins of $\varnothing 10 \mathrm{~mm} \times 20 \mathrm{~mm}$ long have been used for this purpose. End of the pins are polished and cleaned with alcohol before loading them for wear study. Discs made of En24 with no-minal composition of C - $0.41 \%, \mathrm{Mn}-0.57 \%$, $\mathrm{Si}-0.24 \%, \mathrm{~S}-0.01 \%, \mathrm{P}-0.03 \%, \mathrm{Cr}-1.21 \%, \mathrm{Ni}-1.47 \%$, Mo $-0.28 \%$, as per the standard size suitable for the wear tester, were used for this purpose.

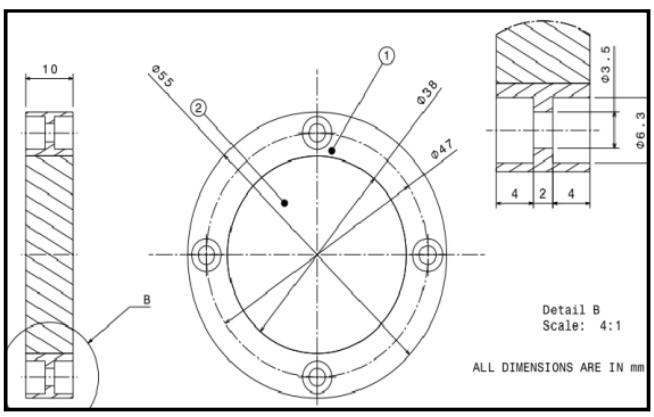

Fig. 16. Details of En24 disc used for the pin on disc wear test.

Surface of disc was polished and cleaned with alcohol and dried before mounting it in the wear tester. Design Expert version 7.0 was used to in developing 32 design matrix to conduct the wear test.

Track Diameter $=20 \mathrm{~mm}$.

Distance Travelled $=1000 \mathrm{~m}$.

Temperature $=20^{\circ} \mathrm{C}$.

Table 3. Factors considered during wear test.

\begin{tabular}{llll}
\hline Factor/Levels & L1 & L2 & L3 \\
\hline Spindle Speed -RPM & 300 & 400 & 500 \\
Load-N & 30 & 40 & 50 \\
\hline
\end{tabular}

The following responses were measured using Ducom Pin on Disc Wear Tester : 
- Weight loss of pin

- Wear rate

- Co-efficient of friction at the interface between pin and disc.

- $\quad$ Frictional force acting at the interface between pin and disc.

The results of Fig.17 assist to infer that co-efficient of friction $(\mu)$ at the interface between pin and disc was found to be lesser in the case of deep cryogenically treated pins than conventionally heat treated pins. For a velocity of $0.314 \mathrm{~m} / \mathrm{sec}$ and a load of $50 \mathrm{~N} \mu$ value is 10 fold in the case of CT pin than DCT pin. For the same load of $50 \mathrm{~N}$ increase in velocity narrows down the difference in $\mu$ between CT and DCT pins. For instance, at load of $50 \mathrm{~N}$ and speed of $0.419 \mathrm{~m} / \mathrm{sec}$ the ratio of $\mu$ between CT and DCT pin is only 7 and it further reduces to 1.36 for velocity of $0.523 \mathrm{~m} / \mathrm{sec}$. It is clearly evident that tribological conditions prevailing at the interface between pin and disc plays significant role on the coefficient of friction and consequently on the frictional force acting at the interface. It is also very sensitive to sliding velocity. Fine precipitates of carbides formed during deep cryogenic treatment increased the wear resistance by dis-persion hardening effect. Probably because of the presence of fine carbides the plastic deformation had not occurred in pins subjected to deep cryogenic treatment. Hence the as-perities that come in contact with each other at the interface lead to condition of minimum frictional coefficient.

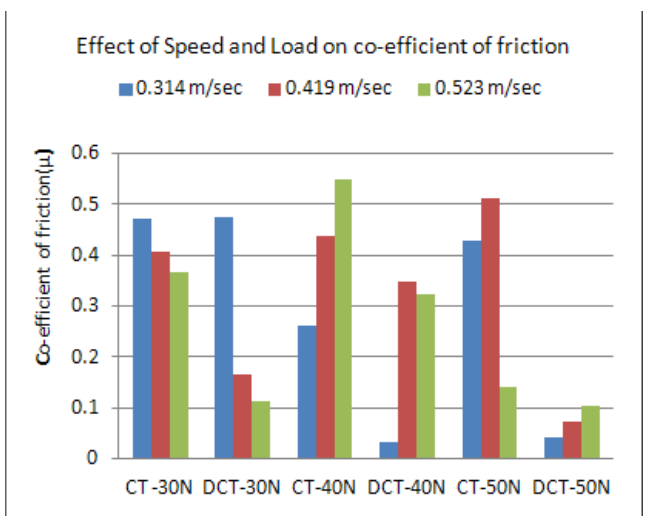

Fig. 17. Comparison graph of Co-efficient of friction at the interface between AISI M35 HSS pin and En24 disc at 3 levels of speeds and loads.

Effect of Speed and Load, on Weight Loss

$\square 0.314 \mathrm{~m} / \mathrm{sec} \quad 0.419 \mathrm{~m} / \mathrm{sec} \quad 0.523 \mathrm{~m} / \mathrm{sec}$

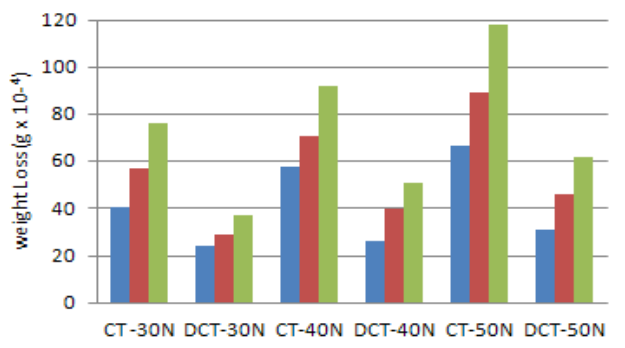

Fig. 18. Comparison graph of weight loss of AISI M35HSS pin at 3 levels speeds and loads.
It was observed that conventional heat treated showed wear rate as high as 6 times that of deep cryogenic treated specimens. Also it was observed that the coefficient of fric-tion at the interface between disc and pin was $30-55 \%$ lesser in the case of deep cryogenic treated specimen. The weight loss of the pin was measured using a digital scale with an accuracy of 10-4 gm. Fig-19 is an image obtained from Ducom Pin on Disc wear tester for a load of $50 \mathrm{~N}$, speed of $0.523 \mathrm{~m} / \mathrm{sec}$ and total distance of $1000 \mathrm{~m}$. It is clearly evident that in about 30 seconds the wear rate stabilized in the case of DCT pin and it took about 150 seconds for CT specimen to cross the unsteady state wear regime.

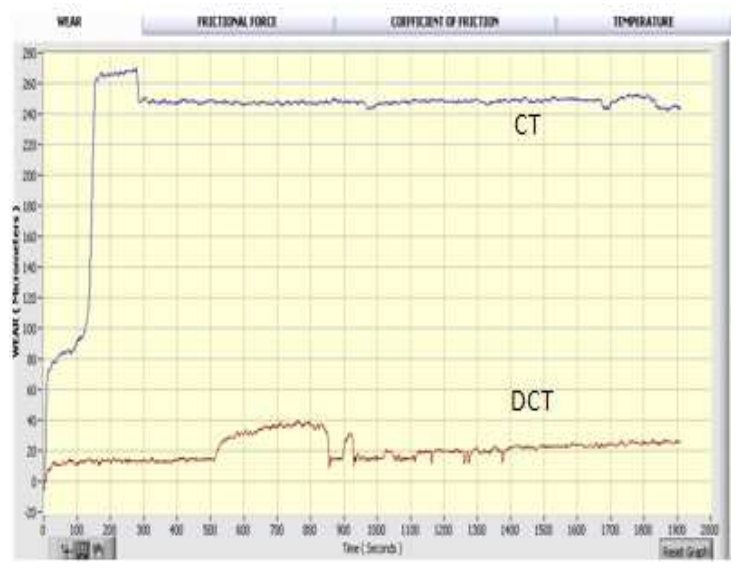

Load $=50 \mathrm{~N}$, Disc Speed $=\mathbf{0 . 5 2 3 \mathrm { m }} / \mathrm{sec}$, Track diameter $=20 \mathrm{~mm}$

Fig. 19. Comparison of Wear Rate of Conventional Heat Treated and Deep Cryogenic Treated Specimen.

\subsection{Morphology of Worn Surface}

The morphology of worn surface of pin observed using SEM reveals the modes of wear that is dominant under the test conditions used in the present study. At a sliding velocity of $0.52 \mathrm{~m} / \mathrm{s}$ and load of $50 \mathrm{~N}$ the observation of worn surface is presented here. The conventional heat treated pins wear by delaminative wear mode. It was observed that on increasing the load to $75 \mathrm{~N}$ the mode of wear shifts to severe delamin-ative mode developing severe cracks and more deforma-tions lips are observed.

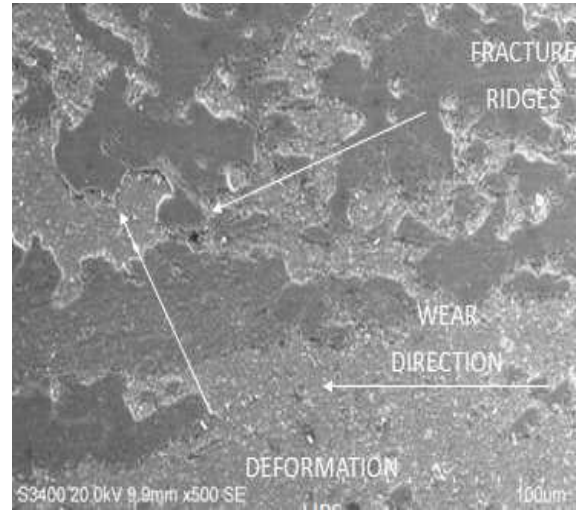

Fig. 20. SEM Image of Worn surface of Conventional Heat Treated Pin Tested in Pin on Disc Wear Tester. 


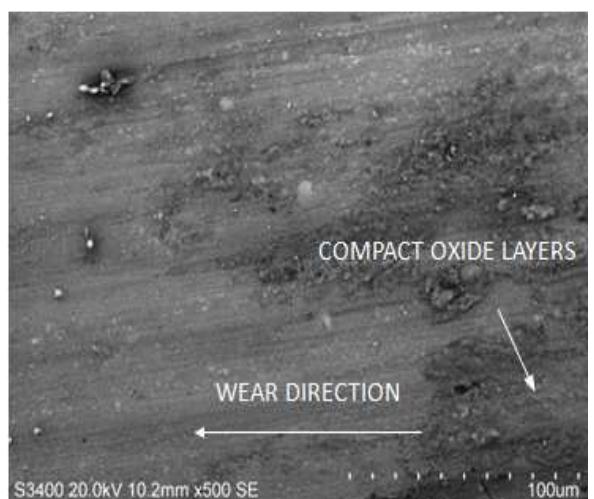

Fig. 21. SEM Image of Worn surface of Deep Cryogenic Treated PIN Tested in Pin on Disc Wear Tester.

The morphology of worn surface of pin observed using SEM reveals the modes of wear that is dominant under the test conditions used in the present study. At a sliding velocity of $0.523 \mathrm{~m} / \mathrm{s}$ and load of $50 \mathrm{~N}$ the observation of worn surface is presented here. The conventional heat treated pins wear by delaminative wear mode. Severe cracks, plastic deformation and more deformations lips are observed.

On the other hand for deep cryogenic treated pins at a sliding velocity of $0.523 \mathrm{~m} / \mathrm{s}$ and load of $50 \mathrm{~N}$ the observa-tion of worn surface reveals that mild oxidative wear mode is dominant. Probably due to the dispersion strengthening mechanism as a result of the formation of fine precipitates of carbides and their uniform distribution in the martensite matrix the wear resistance of the deep cryogenically treated specimen had increased.

\section{Conclusions}

The comparative studies made on the effect of Cryogenic Treatment on AISI M35 grade HSS Tool material assist to infer the following conclusions:

1. Presence of retained austenite from $17-19 \%$ in case of conventional heat treatment has been reduced to $4-5 \%$ by shallow cryogenic treatment and finally it was brought down to less than $1 \%$ by deep cryogenic treatment.

2. There is a marginal improvement in hardness from 64HRC to $64.5 \mathrm{HRC}$ for shallow cryogenic treated specimens. And it improved further after DCT to 65.5HRC.

3. Also the micro hardness measured in Vickers scale shows an increase in hardness value from 920 to 934 in case of shallow cryogenic treatment and it was 980 in case of DCT.

4. Images of microstructure taken at 5000X magnifi-cation shows lot of differences between conven-tional heat treatment and cryogenic treatment. Fine precipitates of secondary carbides are found in shallow cryogenic treated specimens and its popu-lation is found to increase in case of deep cryogenic treatment. Especially around the grain boundaries the fine precipitates carbides of size $0.1-0.3 \mu$ are more in number in case of deep cryogenic treated specimen. Increase in hardness and wear resistance is attributed only to these fine precipitates formed during cryogenic treatment.

5. There was no change in the toughness at the end of deep cryogenic treatment cycle $[1,2,8]$.

6. Wear studies made using pin on disc wear tester shows profound improvement in wear resistance of deep cryogenically treated pins compared to con-ventionally heat treated pins.

\section{Acknowledgements}

The authors acknowledge the services of Centre for Metal Joining and Research, Annamalai University and Nano Technology Department of Periyar Maniammai University for extending their testing facilities.

\section{References}

[1] V.Firouzdor, E.Nejati, F.Khomamizadeh, "Effect of Deep Cryogenic Treatment on Wear Resistance and Tool Life of M2 HSS Drill", Journal of Materials Processing Technology $206,2008,467-472$.

[2] Flavio J. da Silva,Soneso D.Franco,Alisson R. Macha-do,Emmanuel O.Ezugwu, Antonio M.Souza Jr., "Performance of Cryogenically Treated HSS Tools" , Wear 261, 2006, 674-685.

[3] S.Harish, A.Bensely, D.Mohan Lal, A.Rajadurai,GyongyverB.Lenkey "Microstructural Study of Cryogenically Treated En 31 Bearing Steel", Journal of Mate-rials Processing Technology 20 9, 2009, 3351-3357.

[4] A.Akhbarizadeh, A.Shafyei, M.A.Golozar, "Effects of cryo-genic treatment on wear behavior of D6 tool steel", Materials and Design 30 ,2009, 3259-3264.

[5] D.Das, K.K.Ray, A.K.Dutta, "Influence of Temperature of Sub-Zero Treatments on the Wear Behaviour of Die Steel", Wear 267, 20 09, 13 61-1370.

[6] A.Y.L.Yong, K.H.W.Seah, M.Rahman, "Performance Evalu-ation of Cryogenically Treated Tungsten Carbide Tools in Turning", International Journal of Machine Tools \& Manu-facture 46, 2006, $2051-2056$.

[7] T.V.SreeramaReddy, T.Sornakumar, M.VenkataramaReddy, R.Venkatram "Machining Performance of Low Temperature Treated P-30 Tungsten Carbide Cutting Tool Inserts", Cryo-genics 48, 2008, 458-461J.

[8] V.Leskovesk, M.Kalin, J.Vizintin, "Influence of Deep-Cryogenic Treatment on Wear Resistance of Vacuum Heat-Treated HSS”, Vacuum 80, 2006, 507 - 518.

[9] D.Das, A.K.Dutta, K.K.Ray "Correlation of Microstructure with Wear Behaviour of Deep Cryogenically Treated AISI D2 Steel", Wear 267, 2009, 1371-1380.

[10] K.Vadivel, R.Rudramoorthy, "Performance Analysis of Cryogenically Treated Coated Carbide Inserts", International Journal of Advanced Manufacturing Technology,42, 2009, $222-232$. 
[11] Paolo Baldissera, Cristiana Delprete, "Effects of Deep Cryo-genic Treatment on Static Mechanical Properties of 18nicrmo5 Carb.urized Steel", Materials and Design 30, 2009, 435-1440.

[12] Barron, R.F. "Cryogenic treatment of metals to improve wear resistance",Cryogenics 22,1982, 409-414.

[13] P. Baldissera, C. Delprete, "Deep Cryogenic Treatment: A Bibliographic Review" The Open Mechanical Engineering Journal, 2008, 2, 1-11.

[14] Rupinder Singh,Kamaljit Singh, "Enhancement of Tool Ma-terial Characteristics with Cryogenic Treatment: A Re-view",Proceedings of the 2010 International Conference on Industrial Engineering and Operations Management Dha-ka,Bangladesh,January 9- 10,2010.

[15] B.R.Ramji,H.N.Narasimha Murthy,M.Krishna, "Analysis of Roughness and Flank Wear in Turning Grey Cast Iron Using Cryogenically Treated Cutting Tools",Research Journal of Applied Sciences , Engineering and Technology 2(5): 414-417,2010.

[16] M.C.Huang,C.H.Gao, "Study on Cryogenic Phase Change and Wear Characteristic of High Speed Steel",ACTA Metal-lurgica SINICA,Vol.16 No.6,December 2003,pp 524-530.

[17] Lakhwinder Pal Singh,Jagtar Singh, "Effect of Cryogenic Treatment on High Speed Steel Tools",Journal of Engineer- ing and Technology,Jul-Dec2011,Vol 1,Issue 2.

[18] S.Sendooran,P.Raja,"International Journal of Engineering Science and Technology",Vol.3 No.5 May 2011.

[19] Barron RF. Cryogenic Treatment of Metals to Improve Wear Resistance, Cryogenics,22(8),1982 409- 13.

[20] K.H.Prabhudev "Hand Book of Heat Treatment of Steels",1995.

[21] Materials Science and Engineering-William D. Callister, 2010.

[22] D.S.Zamborsky, "Control of distortion in tool steels, in: The heat treating source Book", ASM, 1986, pp. 9-11.

[23] R.E.Smallman,R.J.Bishop "Modern Physical Metallurgy and Materials Engineering"- Sixth edition.

[24] Shivdev Singh, Dilbagh Singh,Nirmal S Kalsi, "Experimental Analysis of Cryogenic Treatment on Coated Tungsten Carbide Inserts in Turning" International Journal of Advanced Engi-neering Technology, Vol III Issue I,2012,290-294.

[25] B.Padgornik,V.Leskovsek,J.Vizintin, "Influence of Deep cryogenic Treatment on Tribological Properties of $\mathrm{P} / \mathrm{M}$ High-Speed Steel" Materials and Manufacturing Process,vol-24,issue 7-8,2009,734-738. 